\title{
Extracellular pH affects the fluorescence lifetimes of metabolic co-factors
}

\author{
Rebecca Schmitz, ${ }^{\text {a,b }}$ Kelsey Tweed, ${ }^{\text {a,b }}$ Christine Walsh, ${ }^{a}$ \\ Alex J. Walsh, ${ }^{\text {a,c,* }}$ and Melissa C. Skala ${ }^{\text {a,b, } *}$ \\ ${ }^{a}$ Morgridge Institute for Research, Madison, Wisconsin, United States \\ buniversity of Wisconsin-Madison, Department of Biomedical Engineering, Madison, \\ Wisconsin, United States \\ 'Texas A\&M University, Department of Biomedical Engineering, College Station, Texas, \\ United States
}

\begin{abstract}
Significance: Autofluorescence measurements of the metabolic cofactors NADH and flavin adenine dinucleotide (FAD) provide a label-free method to quantify cellular metabolism. However, the effect of extracellular $\mathrm{pH}$ on flavin lifetimes is currently unknown.

Aim: To quantify the relationship between extracellular $\mathrm{pH}$ and the fluorescence lifetimes of FAD, flavin mononucleotide (FMN), and reduced nicotinamide adenine dinucleotide (phosphate) $[\mathrm{NAD}(\mathrm{P}) \mathrm{H}]$.

Approach: Human breast cancer (BT474) and HeLa cells were placed in pH-adjusted media. Images of an intracellular $\mathrm{pH}$ indicator or endogenous fluorescence were acquired using twophoton fluorescence lifetime imaging. Fluorescence lifetimes of FAD and FMN in solutions were quantified over the same $\mathrm{pH}$ range.

Results: The relationship between intracellular and extracellular $\mathrm{pH}$ was linear in both cell lines. Between extracellular $\mathrm{pH} 4$ to 9, FAD mean lifetimes increased with increasing $\mathrm{pH}$. $\mathrm{NAD}(\mathrm{P}) \mathrm{H}$ mean lifetimes decreased with increasing $\mathrm{pH}$ between extracellular $\mathrm{pH} 5$ to 9 . The relationship between $\mathrm{NAD}(\mathrm{P}) \mathrm{H}$ lifetime and extracellular $\mathrm{pH}$ differed between the two cell lines. Fluorescence lifetimes of FAD, FAD-cholesterol oxidase, and FMN solutions decreased, showed no trend, and showed no trend, respectively, with increasing $\mathrm{pH}$.

Conclusions: Changes in endogenous fluorescence lifetimes with extracellular $\mathrm{pH}$ are mostly due to indirect changes within the cell rather than direct $\mathrm{pH}$ quenching of the endogenous molecules.

(C) The Authors. Published by SPIE under a Creative Commons Attribution 4.0 Unported License. Distribution or reproduction of this work in whole or in part requires full attribution of the original publication, including its DOI. [DOI: 10.1117/1.JBO.26.5.056502]
\end{abstract}

Keywords: autofluorescence; flavin adenine dinucleotide; NADH; fluorescence lifetime; pH; BT474; HeLa.

Paper 210047LR received Feb. 10, 2021; accepted for publication May 11, 2021; published online May 25, 2021.

\section{Introduction}

Two-photon fluorescence lifetime imaging (FLIM) of endogenous fluorophores can noninvasively monitor metabolic activity on a cellular level. ${ }^{1}$ Endogenous fluorophores related to metabolism include flavin adenine dinucleotide (FAD), reduced nicotinamide adenine dinucleotide (phosphate) $(\mathrm{NAD}(\mathrm{P}) \mathrm{H})$, and flavin mononucleotide (FMN). FAD and FMN are fluorescent flavins, in which FAD is more prevalent in the cell. ${ }^{2,3}$ FAD and FMN are primarily localized in the mitochondria and bound to enzymes as a cofactor, although some proteins that use FAD or FMN as a cofactor are localized to other parts of the cell. ${ }^{4,5}$ Fluorescence spectra of NAD(P)H, FAD, and FMN have been previously published. ${ }^{3,6,7}$ The fluorescence spectra of FAD and FMN

*Address all correspondence to Alex. J. Walsh,walshaj@tamu.edu; Melissa C. Skala, mcskala@wisc.edu 
show substantial overlap, so FMN may contribute to FAD lifetime in FLIM measurements. ${ }^{3}$ $\mathrm{NAD}(\mathrm{P}) \mathrm{H}$ and FAD each have two distinct lifetimes due to free- and protein-bound states. For $\mathrm{NAD}(\mathrm{P}) \mathrm{H}$, the short lifetime $\left(\tau_{1}\right)$ corresponds to free, unbound $\mathrm{NAD}(\mathrm{P}) \mathrm{H}$, and the long lifetime $\left(\tau_{2}\right)$ corresponds to protein-bound $\mathrm{NAD}(\mathrm{P}) \mathrm{H} .{ }^{8}$ Conversely, for FAD, free FAD has a long lifetime, and protein-bound FAD has a short lifetime. ${ }^{9}$

Given that FLIM of endogenous fluorescence is highly sensitive to cellular changes in metabolism, it has been used in many biomedical applications, including detection and treatment of cancer, tissue metabolism, and pathologies in the skin and eye. ${ }^{10-17}$ Fluorescence lifetimes are sensitive to a number of environmental factors, including $\mathrm{pH}$, oxygen levels, and temperature. ${ }^{10,11,18,19}$ Extracellular $\mathrm{pH}$ is particularly relevant, as its effects on the internal $\mathrm{pH}$ of the cell may result in a suboptimal $\mathrm{pH}$ for metabolic enzymes to function or disrupt the proton gradient within mitochondria. ${ }^{20}$ Extracellular $\mathrm{pH}$ is typically maintained in interstitial fluid around $\mathrm{pH} 7.4 .^{21}$ In some tissues, such as the GI system, the extracellular $\mathrm{pH}$ varies. In the intestinal tract, the $\mathrm{pH}$ may be as high as 8.0 or low as 4.0 , and as low as 1.0 in the stomach. ${ }^{22}$ The extracellular $\mathrm{pH}$ is altered in common pathologies such as COPD, renal failure, and ischemia. The extracellular environment in tumors may also be more acidic (approximately pH 6.2 to 6.9) than healthy tissues. ${ }^{23-25}$ Studies in tumors have demonstrated that $\mathrm{pH}$ changes inside and outside the tumor are a major factor in promotion of tumor growth and metastasis. ${ }^{23,26}$

Several studies have investigated how $\mathrm{pH}$ affects the lifetime of various endogenous fluorophores. $\mathrm{NAD}(\mathrm{P}) \mathrm{H}$ mean lifetime in cells decreased with increased extracellular $\mathrm{pH} .{ }^{19,20}$ Other studies focused on intracellular $\mathrm{pH}$, using nigericin to equalize intracellular and extracellular $\mathrm{pH}$ across the cell membrane. These studies found NAD(P)H and FAD mean lifetimes decreased with increased intracellular $\mathrm{pH}^{27,28}$ However, using nigericin/K+ to equalize $\mathrm{pH}$ across the membrane presents a confounding factor when used in conjunction with FLIM of metabolic cofactors. Nigericin decreases ATP concentrations, lowers the rate of protein synthesis, and affects the intracellular levels of other molecules, such as lactate. ${ }^{29-31}$ It is unclear whether the effects of nigericin are due to the presence of the molecule itself, or due to the changes in ion concentration and $\mathrm{pH}$ that result. At least, one study suggests that nigericin affects metabolites independently of its effects on ion concentrations. ${ }^{29}$ When nigericin/K+ equilibration is used with FLIM of NAD(P)H and FAD, molecules highly sensitive to metabolic changes, it may affect the results of such experiments. Since several studies have used nigericin to control intracellular $\mathrm{pH}$, the effects of $\mathrm{pH}$, independent of nigericin, on the fluorescence lifetimes of $\mathrm{NAD}(\mathrm{P}) \mathrm{H}$ and FAD remain ambiguous.

In addition, manipulation of extracellular $\mathrm{pH}$ often occurs in cell culture, as well as in other contexts, during FLIM experiments. For example, many cell media rely on $\mathrm{CO}_{2}$-dependent buffers to maintain media $\mathrm{pH}$. If $\mathrm{CO}_{2}$ level is not maintained throughout the experiment, the buffer may no longer keep the extracellular $\mathrm{pH}$ consistent. Understanding the effects of extracellular $\mathrm{pH}$ on endogenous fluorescence lifetimes could improve the accuracy and reproducibility of in vitro and in vivo studies. Studies of extracellular $\mathrm{pH}$ effects on FAD lifetime are absent from the existing literature. Additionally, few studies have investigated $\mathrm{pH}$ effects on coenzyme lifetimes in more than one cell line, limiting our understanding of how extracellular $\mathrm{pH}$ may influence endogenous fluorescence lifetimes in different cell types. ${ }^{19}$

To further investigate the effects of extracellular $\mathrm{pH}$ on the fluorescence lifetimes of FAD, FMN, and $\mathrm{NAD}(\mathrm{P}) \mathrm{H}$, human breast cancer (BT474) and HeLa cells were placed in $\mathrm{pH}$ adjusted media and imaged using two-photon FLIM. Additionally, 5-(and-6)-carboxy SNARF-1, a fluorescent intracellular $\mathrm{pH}$ indicator, was added to cells in a separate experiment to study the relationship between extracellular and intracellular $\mathrm{pH}$ changes. To investigate how these lifetime changes due to $\mathrm{pH}$ relate to the chemical properties of flavins, FAD (free and bound to cholesterol oxidase) and FMN solutions were prepared at varying pHs and imaged using FLIM.

\section{Methods}

\subsection{FLIM of Cells and Solutions}

BT474 cells (HER2 overexpressing human breast cancer cells) and HeLa cells were grown in Dubecco's modified eagle medium (DMEM) supplemented with $10 \%$ fetal bovine serum and 
$1 \%$ penicillin: streptomycin. BT474 cells and HeLa cells were plated on glass-bottomed imaging dishes at $\sim 100,000$ cells $/ \mathrm{cm}^{2} 24 \mathrm{~h}$ before imaging.

BT474 and HeLa cell samples were imaged in pH-adjusted DMEM media containing HEPES to maintain a consistent $\mathrm{pH}$ during imaging. The media $\mathrm{pH}$ was adjusted using $1.0 \mathrm{M} \mathrm{NaOH}$ and $1.0 \mathrm{M} \mathrm{HCl}$ to the desired $\mathrm{pH}$ for the sample, within a range of $\mathrm{pH} 4$ to 9. This range of extracellular $\mathrm{pH}$ conditions includes much of the range of extracellular $\mathrm{pH}$ found in biological tissues. ${ }^{21-25}$ Cell samples were maintained in regular DMEM until 30 min before imaging, when the media were replaced with the $\mathrm{pH}$-adjusted media. The control samples were imaged in non-pH-adjusted DMEM media containing HEPES. Dishes were imaged outside of incubation, so $\mathrm{CO}_{2}$ was present at atmospheric concentrations. These cells were imaged in media containing HEPES buffer. As HEPES buffer does not rely on $\mathrm{CO}_{2}$ for buffering capacity, this kept $\mathrm{pH}$ levels constant from the time of the initial media change through the end of imaging. Measurements of media $\mathrm{pH}$ performed after the experiment confirmed that the $\mathrm{pH}$ had not changed during imaging.

FAD salt hydrate (\#F6625), cholesterol oxidase enzyme from Streptomyces sp. (\#C8649), and FMN salt hydrate (\#F2253) were purchased from Sigma Aldrich. FMN and FAD solutions were prepared in phosphate buffered saline, and cholesterol oxidase enzyme solutions were prepared in a $50-\mathrm{mM}$ potassium phosphate buffer. All solutions were adjusted to a range of $\mathrm{pH}$ values, between $\mathrm{pH} 5$ and 9, using $1.0 \mathrm{M} \mathrm{HCl}$ and $1.0 \mathrm{M} \mathrm{NaOH}$. FMN was imaged at a concentration of $34 \mu \mathrm{mol} / \mathrm{L}$ and FAD at $340 \mu \mathrm{mol} / \mathrm{L}$. The purchased cholesterol oxidase was non-covalently bound to FAD in a powdered form, so no additional FAD was added to these solutions. ${ }^{32}$ The solutions of cholesterol oxidase and FAD were dissolved in buffer and imaged at a concentration of $0.81 \mu \mathrm{mol} / \mathrm{L}$.

All samples were imaged with a custom-built multiphoton fluorescence microscope (Ultima, Bruker) equipped with time correlated single photon counting electronics (SPC-150, Becker \& Hickl GmbH, Berlin, Germany). A 40× (NA $=1.15)$ water immersion objective was used and the imaging field of view was $270 \mu \mathrm{m} \times 270 \mu \mathrm{m}(256 \times 256$ pixels). The laser (Insight DS+, Spectra-Physics Inc., Santa Clara, CA, USA) was tuned to $750 \mathrm{~nm}$ for NAD(P)H excitation and $890 \mathrm{~nm}$ for FAD and/or FMN excitation. Fluorescence emission was isolated with $440 / 80 \mathrm{~nm}$ bandpass filter for NAD(P)H and a 540/80 nm bandpass filter for FAD and/or FMN.${ }^{3,6,7}$ Fluorescence emission was detected with a H7422PA-40 GaAsP photomultiplier tube (Hamamatsu Corporation, Bridgewater, NJ, USA). Powers on the sample ranged from 3.0 to $5.0 \mathrm{~mW}$ (not including the SNARF measurements, which were measured at an average power of $0.3 \mathrm{~mW}$ ). Control dishes were used for the purpose of checking for uniform excitation across the field of view. All images in this experiment were uniformly illuminated. A measured instrument response function (IRF) was also taken each day as a standard from the second harmonic generation of a urea crystal.

The decay curves for each pixel were obtained by binning each pixel with the eight surrounding pixels. The decay curves were then deconvolved using the measured IRF. In cells and cholesterol oxidase solutions, the resulting decay was fit to a two-component exponential decay function. This accounts for the two distinct lifetimes of $\mathrm{NAD}(\mathrm{P}) \mathrm{H}$ and FAD in the free and protein-bound state in cells. ${ }^{8,9}$ For $\mathrm{NAD}(\mathrm{P}) \mathrm{H}, \alpha_{1}$ and $\tau_{1}$ correspond to free $\mathrm{NAD}(\mathrm{P}) \mathrm{H}$; whereas for FAD, $\alpha_{1}$ and $\tau_{1}$ correspond to protein-bound FAD. We note that a two-component fit at $890 \mathrm{~nm}$ does not account for the possibility of three species (protein-bound FAD, free FAD, and FMN) and that FMN may contribute to the long lifetime at $890 \mathrm{~nm} \cdot{ }^{33}$ However, the use of a two-component fit enables comparisons to previous studies in cells that also use a twocomponent fit for the FAD channel ${ }^{15,16,34-36}$ and reduces the binning needed for reliable fits. For the cholesterol oxidase solutions, some of the FAD dissociated from the enzyme in the dissolution of the powder, so a two-exponential fit was used. The two-exponential fit function is

$$
I(t)=\alpha_{1} e^{-\frac{t}{\tau_{1}}}+\alpha_{2} e^{-\frac{t}{\tau_{2}}}+C,
$$

where $I(t)$ is the light intensity at time $t$ following the laser pulse, $\tau_{1}$ and $\tau_{2}$ represent the shortand long-fluorescence lifetimes of the fluorophore, and $\alpha_{1}$ and $\alpha_{2}$ represent the fractional contribution of each fluorescence lifetime. ${ }^{9,12} C$ accounts for the presence of background light. A mean lifetime $\left(\tau_{m}\right)$ was also obtained for each pixel using the formula $\tau_{m}=\alpha_{1} \tau_{1}+\alpha_{2} \tau_{2}$. 
In FAD and FMN solution images, the decay at each pixel was fit to a one-component exponential decay function. These steps were carried out in SPCImage (Becker \& Hickl).

For cell images, automated segmentation of cell cytoplasms was performed in CellProfiler. ${ }^{37}$ Nuclear regions of the cells were segmented by identifying pixels that were darker than the surrounding cytoplasm, but brighter than the background. The resulting round objects with diameter 10 to 40 pixels were saved as nuclei. Cells were identified by propagating out from the nuclei, using a threshold to prevent propagation into the background. Cell cytoplasm was defined as the cell region minus the nuclear region. 25 to 125 cells per sample were segmented. Values of fluorescence lifetime variables (FAD $\tau_{m}$, FAD $\tau_{1}$, FAD $\tau_{2}$, FAD $\alpha_{1}, \operatorname{NAD}(\operatorname{P}) \mathrm{H} \tau_{m}$, $\left.\mathrm{NAD}(\mathrm{P}) \mathrm{H} \tau_{1}, \mathrm{NAD}(\mathrm{P}) \mathrm{H} \tau_{2}, \mathrm{NAD}(\mathrm{P}) \mathrm{H} \alpha_{1}\right)$ as well as the optical redox ratio (defined as $\mathrm{NAD}(\mathrm{P}) \mathrm{H}$ intensity divided by the sum of $\mathrm{NAD}(\mathrm{P}) \mathrm{H}$ and $\mathrm{FAD}$ intensities) were calculated for each cell cytoplasm. The lifetimes of solution images were calculated for each pixel and averaged on an image level. Calculations were performed using MATLAB and R.

\subsection{Intensity Imaging of $\mathrm{pH}$ Indicator SNARF-1}

To study the relationship of extracellular $\mathrm{pH}$ and intracellular $\mathrm{pH}$ using an intracellular $\mathrm{pH}$ indicator, new samples of BT474 and HeLa cells were prepared and imaged separately from the FLIM experiments. Before imaging, a $10 \mu \mathrm{mol} / \mathrm{L}$ solution of 5-(and-6)-carboxy SNARF-1 (acetoxymethyl ester acetate), a fluorescent pH-sensitive compound (\#C1272, Fisher Scientific), was prepared in serum-free DMEM. The cells were incubated in the $10 \mu \mathrm{mol} / \mathrm{L}$ SNARF-1 solution for $30 \mathrm{~min}$. Following incubation, a pH-adjusted HEPES-containing media (pHs 4, $5,6,7,8$, and 9) replaced the SNARF-1 solution.

Nigericin equilibrizes intracellular and extracellular $\mathrm{pH}$ and was used for calibration purposes in the SNARF-1 calibration experiments only. Nigericin (\#N1495, Fisher Scientific) at $10 \mu \mathrm{mol} / \mathrm{L}$ was prepared in buffer solutions (\#P35379, Fisher Scientific) at pHs 4.5, 5.5, 6.5, 7.5, and 8.5. New samples of BT474 and HeLa cells were treated with the SNARF-1 solution for $30 \mathrm{~min}$, then a nigericin-buffer solution was added to calibrate intracellular $\mathrm{pH}$ to the $\mathrm{pH}$ of the buffer.

Intensity images of the SNARF-1 fluorescence were collected using two-photon microscopy (as described above) for both experimental dishes (cells treated with $\mathrm{pH}$-adjusted HEPEScontaining DMEM media, no nigericin) and calibration dishes (cells treated with nigericin buffer solutions). The laser was tuned to $900 \mathrm{~nm}$ (average power: $0.3 \mathrm{~mW}$ ) for SNARF-1 excitation. A 650/45 nm bandpass filter collected the pH-dependent SNARF-1 emission. ${ }^{38}$ A second lowpass filter collected all emission $<575 \mathrm{~nm}$ to establish an isoemissive baseline for all samples. To create a calibration curve, the ratio of the intensity of the $\mathrm{pH}$-dependent emission $(650 / 45 \mathrm{~nm}$ bandpass) to baseline ( $575 \mathrm{~nm}$ low pass) was fit to a sigmoidal curve plotted against $\mathrm{pH}$ for each cell line treated with nigericin (calibration dishes). ${ }^{39}$ Intracellular $\mathrm{pH}$ values of the experimental dishes were found by calculating the SNARF1 intensity ratio (intensity of 650/45 nm bandpass divided by intensity of $575 \mathrm{~nm}$ low pass) and calculating $\mathrm{pH}$ from the sigmoidal fit of the calibration curve from the same cell line.

\subsection{Statistics}

Statistical analysis was performed in $\mathrm{R}$. The linear correlation between $\mathrm{pH}$ and fluorescence variables in BT474 and HeLa cells was determined using the Pearson correlation coefficient. The statistical significance between Pearson correlations was determined using the Pearson $R$-to- $z$ transformation. Statistical significance between $\mathrm{pH}$ conditions of the FAD, cholesterol oxidase, and FMN solutions was calculated using one-way ANOVA followed by Tukey's HSD test.

\section{Results}

Representative images of the SNARF1 intensity ratio in calibration condition (nigericin treated) HeLa cells demonstrated a qualitative increase in the intensity ratio as the $\mathrm{pH}$ increased from $\mathrm{pH}$ 4 to $\mathrm{pH} 9$ [Fig. 1(a)]. This was further supported by the quantitative calibration data, showing a 
$\mathrm{pH} 4.0$
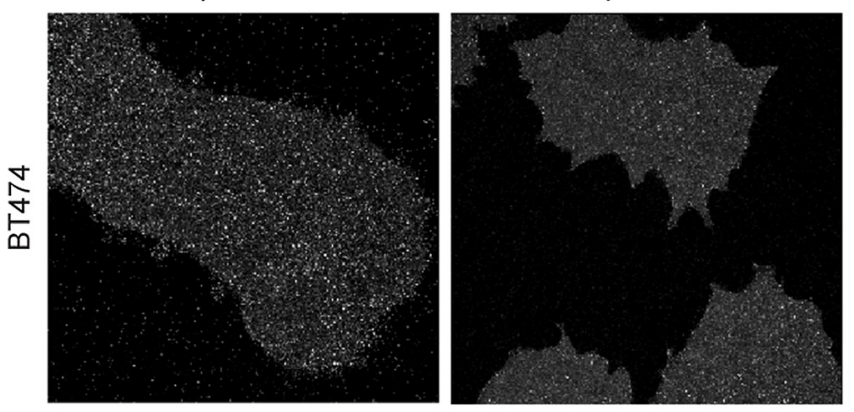

(a)

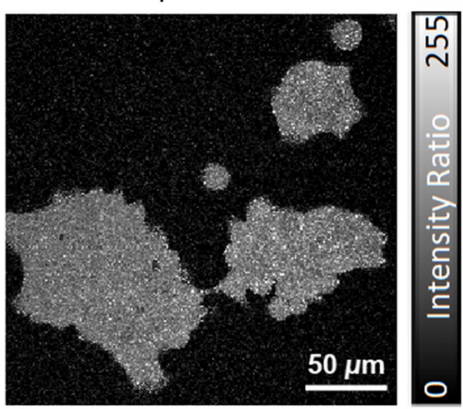

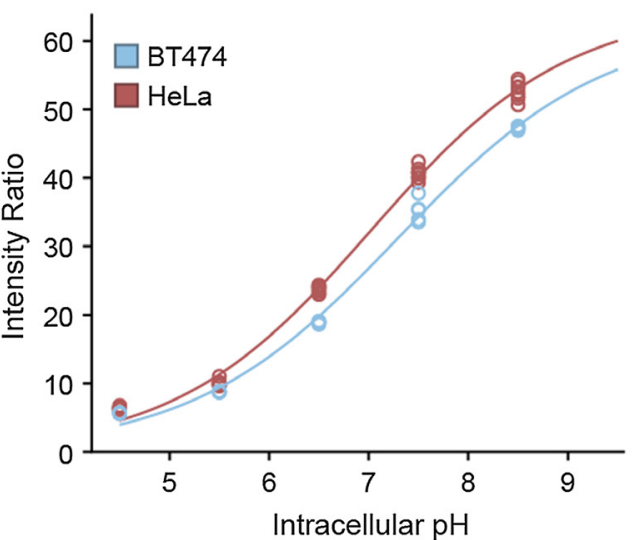

(b)

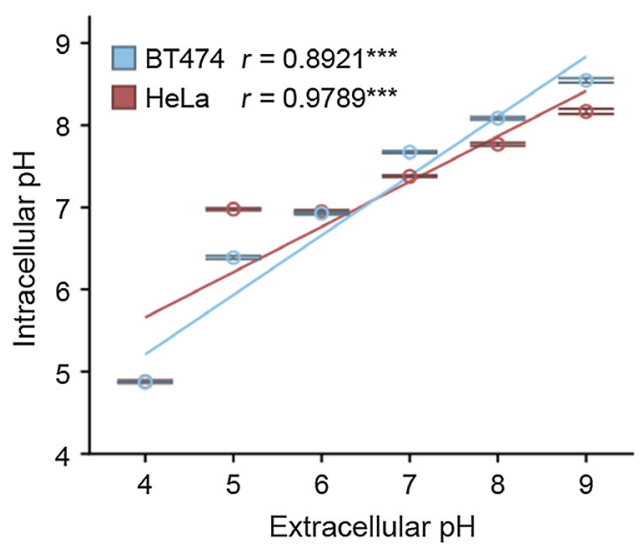

(c)

Fig. 1 SNARF-1 measurement of intracellular $\mathrm{pH}$. (a) Representative images of the intensity ratio of SNARF-1 fluorescent dye in BT474 cells. Intensity ratio is calculated on an image level and is equal to the intensity of the $\mathrm{pH}$-dependent SNARF-1 intensity at $650 / 45 \mathrm{~nm}$ bandpass divided by the isoemissive SNARF-1 intensity at $575 \mathrm{~nm}$ low pass. (b) Calibration curve in BT474 (blue) and HeLa (red) cells, fit to a sigmoidal curve $(n=65$ images, $n=25$ images, respectively; each dot corresponds to one image). (c) Intracellular pH versus extracellular pH in BT474 (blue) and HeLa (red) cells, mean $\pm 95 \%$ confidence intervals ( $n=48$ images, $R=0.8785$ and $n=30$ images, $R=0.9789$, respectively). ${ }^{\star \star \star} P<0.001$. $R$-values correspond to Pearson correlation coefficients.

sigmoidal relationship between the intensity ratio of SNARF-1 and the intracellular $\mathrm{pH}$ in both cell lines [Figs. 1(b) and 1(c)]. Using these calibration curves to calculate the intracellular $\mathrm{pH}$ in the experimental condition (no nigericin), a strong positive correlation between extracellular $\mathrm{pH}$ and intracellular $\mathrm{pH}$ emerged, present in both HeLa and BT474 cells [Figs. 1(d) and 1(e)]. The Pearson correlation coefficient $(R)$ for this relationship was 0.8921 in BT474 cells and 0.9789 in HeLa cells.

The SNARF-1 data demonstrated the existence of a strong positive correlation between the extracellular and intracellular $\mathrm{pH}$ in BT474 and HeLa cells. Therefore, altering environmental $\mathrm{pH}$ does affect the intracellular $\mathrm{pH}$. Given the $\mathrm{pH}$ dependence of many enzymes and metabolic processes, this is especially relevant for studies of metabolism. The relationship between intracellular and extracellular $\mathrm{pH}$ characterized in this assay is consistent with other studies investigating the same relationship. ${ }^{20,39,40}$

Representative images of $\mathrm{NAD}(\mathrm{P}) \mathrm{H} \tau_{m}$ and FAD $\tau_{m}$ in HeLa cells qualitatively demonstrated an increase in FAD $\tau_{m}$ with increasing extracellular $\mathrm{pH}$, and higher $\mathrm{NAD}(\mathrm{P}) \mathrm{H} \tau_{m}$ at $\mathrm{pH} 7$ compared to $\mathrm{pH} 4$ and $\mathrm{pH} 9$ [Fig. 2(a)]. The FAD $\tau_{m}$ trends were also demonstrated in the quantitative data, which showed a moderate linear correlation between extracellular $\mathrm{pH}$ and FAD $\tau_{m}$ in both BT474 and HeLa cells ( $R=0.6520$ and $R=0.4914$ in BT474 and HeLa cells, respectively) [Fig. 2(b)]. Conversely, the overall linear correlation between $\mathrm{NAD}(\mathrm{P}) \mathrm{H} \tau_{m}$ and extracellular $\mathrm{pH}$ was weakly positive in HeLa cells and moderately negative in BT474 cells [Fig. 2(c)]. However, with the $\mathrm{pH} 4$ group excluded, NAD(P)H $\tau_{m}$ showed a moderately negative linear correlation with extracellular $\mathrm{pH}(R=-0.7627$ and $R=-0.5655$ in BT474 and HeLa cells, 

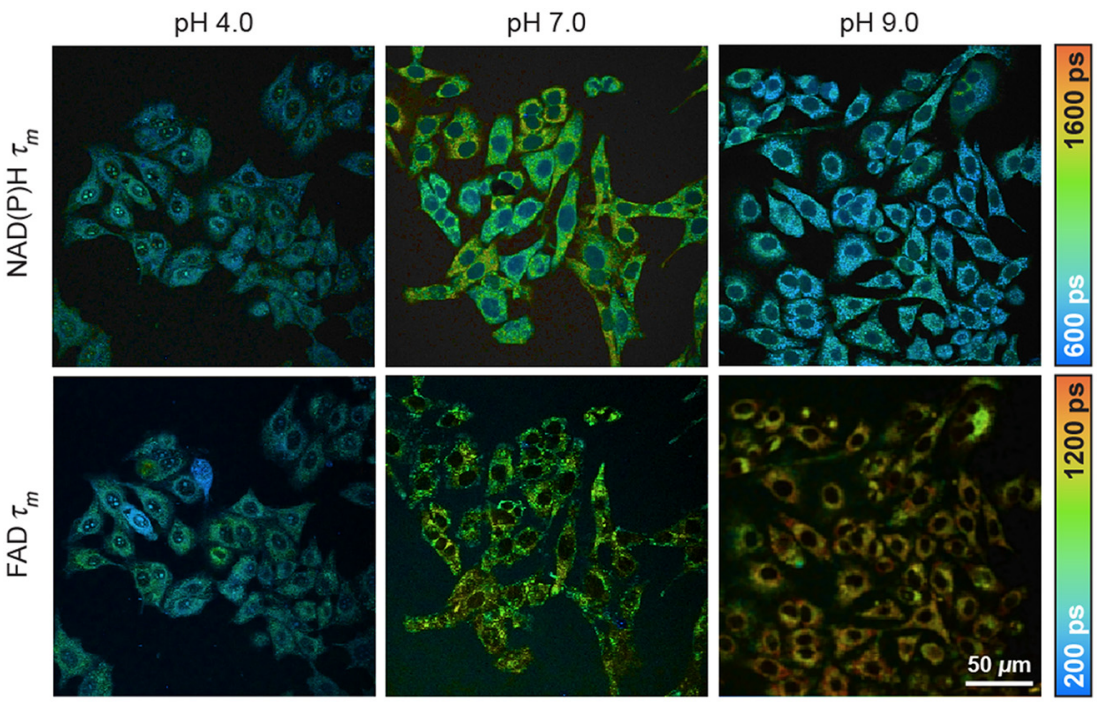

(a)

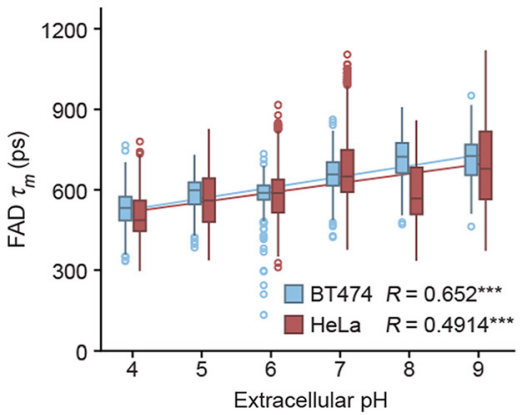

(b)

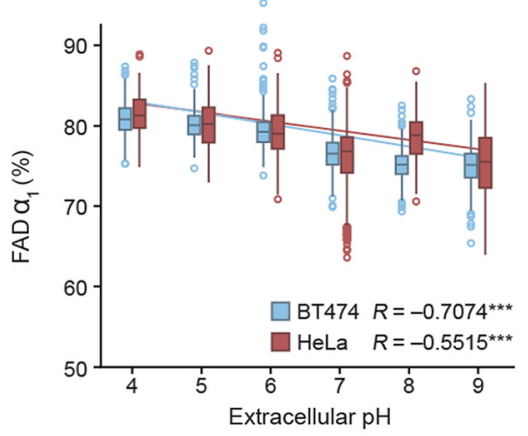

(d)

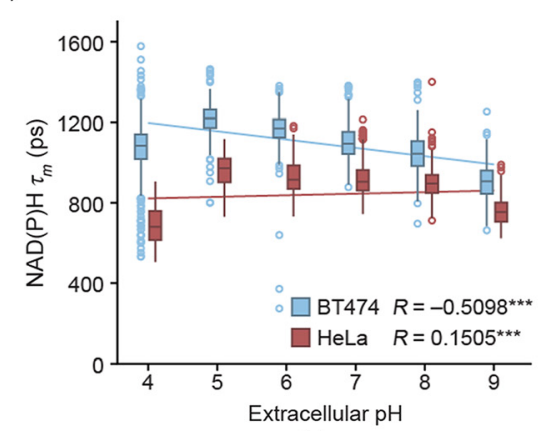

(c)

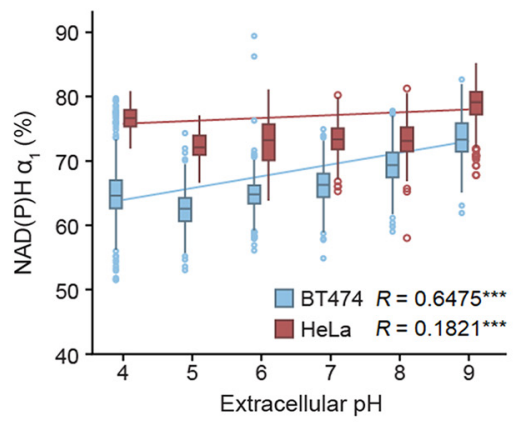

(e)

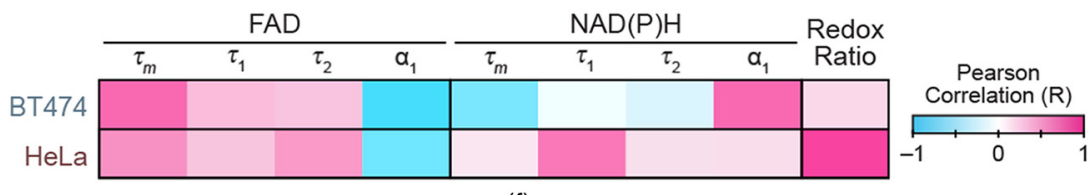

(f)

Fig. 2 FLIM of BT474 and HeLa cells vary with extracellular $\mathrm{pH}$. (a) Representative images of $\mathrm{NAD}(\mathrm{P}) \mathrm{H} \tau_{m}$ and FAD $\tau_{m}$ in HeLa cells at $\mathrm{pH}$ 4.0, $\mathrm{pH} 7.0$, and $\mathrm{pH} 9.0$ in pseudocolor. (b) Box-and-whisker plot of FAD $\tau_{m}$ versus extracellular $\mathrm{pH}$. Box is centered at median and reaches to first and third quartiles. Whiskers reach to $1.5 \times$ interquartile range with dots as outliers beyond this range. (c) Box-and-whisker plot of $\mathrm{NAD}(\mathrm{P}) \mathrm{H} \tau_{m}$ versus extracellular $\mathrm{pH}$. (d) Box-andwhisker plot of FAD $\alpha_{1}$ versus extracellular $\mathrm{pH}$. (e) Box-and-whisker plot of $\mathrm{NAD}(\mathrm{P}) \mathrm{H} \alpha_{1}$ versus extracellular $\mathrm{pH}$. Blue = BT474, red = HeLa. (f) Heatmap of Pearson correlations, measuring the linear correlation with $\mathrm{pH}$ for all metabolic parameters in both cell lines, for the extracellular $\mathrm{pH}$ range 4 to 9; all $R$-values are significant at $p<0.05$. $n=4831$ cells for $\mathrm{BT} 474, n=3870$ cells for HeLa. $R$ values correspond to Pearson correlation coefficients. ${ }^{\star \star \star} P<0.001$. 
respectively). In addition, $\mathrm{NAD}(\mathrm{P}) \mathrm{H} \tau_{m}$ increased from $\mathrm{pH} 4$ to $\mathrm{pH} 5$ in both $\mathrm{BT} 474$ and HeLa cells.

We then investigated which parameters contributed to the mean lifetime trends. In these results, $\alpha_{1}$ and $\tau_{1}$ correspond to free $\mathrm{NAD}(\mathrm{P}) \mathrm{H}$ and protein-bound FAD. Increases in FAD $\tau_{m}$ with increasing extracellular $\mathrm{pH}$ were driven primarily by a decrease in FAD $\alpha_{1}$ with increasing extracellular $\mathrm{pH}$ [Fig. 2(d)]. The trend in $\mathrm{NAD}(\mathrm{P}) \mathrm{H} \tau_{m}$ appears to have been driven by different components between the two cell types. In BT474 cells, there was a moderate linear correlation in $\mathrm{NAD}(\mathrm{P}) \mathrm{H} \alpha_{1}$ with increasing extracellular $\mathrm{pH}[R=0.6475$, Fig. 2(e)]. These results indicate an increase in the amount of free $\mathrm{FAD}$ and $\mathrm{NAD}(\mathrm{P}) \mathrm{H}$ [due to increased FAD $\alpha_{2}$ and $\mathrm{NAD}(\mathrm{P}) \mathrm{H} \alpha_{1}$ ] when extracellular $\mathrm{pH}$ increases in BT474 cells. The linear correlation between $\mathrm{NAD}(\mathrm{P}) \mathrm{H} \tau_{m}$ and extracellular $\mathrm{pH}$ was weaker in HeLa cells $[R=0.1821$, Fig. 2(e)]. In contrast, $\mathrm{NAD}(\mathrm{P}) \mathrm{H} \tau_{m}$ in HeLa cells was more strongly driven by decreased $\mathrm{NAD}(\mathrm{P}) \mathrm{H} \tau_{1}$ with increasing extracellular $\mathrm{pH}\left[R=0.5960\right.$, Fig. 2(f)]. FAD $\tau_{1}$, FAD $\tau_{2}$, and $\mathrm{NAD}(\mathrm{P}) \mathrm{H} \tau_{2}$ had moderate to weak linear correlations with extracellular $\mathrm{pH}$ in both cell lines [Fig. 2(f)]. The redox ratio in HeLa cells demonstrated a strong linear correlation with extracellular $\mathrm{pH}(R=0.8059)$, but the correlation was much weaker in BT474 cells $[R=0.2091$, Fig. 2(f)].

These data suggested that extracellular $\mathrm{pH}$ affects the lifetimes of both FAD and $\mathrm{NAD}(\mathrm{P}) \mathrm{H}$ in the cells. FAD $\tau_{m}$ linearly decreases between extracellular $\mathrm{pH} 4$ to 9 . NAD $(\mathrm{P}) \mathrm{H} \tau_{m}$ linearly decreases between extracellular $\mathrm{pH} 5$ to 9 , with $\mathrm{pH} 4$ breaking this trend. Interestingly, the trends and the strength of correlations between fluorescence lifetime variables and extracellular $\mathrm{pH}$ were not the same in both cell lines, with differences particularly evident in the NAD $(\mathrm{P}) \mathrm{H}$ lifetime variables and the optical redox ratio [Fig. 2(f)]. This suggests that the extracellular $\mathrm{pH}$ may not affect the metabolism of every cell line in the same way or to the same degree.

In the FAD solutions [Fig. 3(a)], the magnitude of changes in FAD lifetime was small from pH 5 to 9 , with a range of 2414 to 2534 ps. The FAD lifetime decreased with increasing solution $\mathrm{pH}[R=-0.8375$, Fig. 3(a)], and the FAD lifetime in solution was significantly different from the $\mathrm{pH} 7$ control at $\mathrm{pH} 5$ and $\mathrm{pH}$ 9.2. FMN lifetime in solution [Fig. 3(b)] also exhibited only small changes, with a range of 3591 to 3704 ps over pH 5 to 9. Significant changes in FMN lifetime, compared to the control group at $\mathrm{pH} 7$, occurred only in the $\mathrm{pH} 5$ and $\mathrm{pH} 9$ groups [Fig. 3(b)]. Cholesterol oxidase solutions containing FAD were fit to two components to account for both bound and free FAD. The proportion of free, unbound FAD in solution was $33.26 \% \pm 5.19 \%$. Both FAD $\tau_{1}$ (bound FAD) and FAD $\tau_{2}$ (free FAD) were significantly different from the control pH 7 only at pH 5 [Figs. 3(c) to 3(d)].

FAD $\tau_{2}$ trends in the cholesterol oxidase solutions differed from the FAD lifetime in solutions of FAD alone, but this difference may be attributed to the presence of cholesterol oxidase and its $\mathrm{pH}$ dependence in addition to $\mathrm{pH}$-influenced changes in FAD itself. Cholesterol oxidase activity has been shown to vary with changes in $\mathrm{pH}^{41}$ These changes in FAD and FMN lifetimes in solutions over pH 5 to 9 (Fig. 3) do not account for the observed changes in vitro in HeLa and BT474 cells (Fig. 2). This indicates that changes in flavin lifetimes observed in vitro are likely due to metabolic changes within the cell in response to $\mathrm{pH}$ rather than local changes in $\mathrm{pH}$ alone.

\section{Conclusions}

The results of this study demonstrate that alterations in extracellular $\mathrm{pH}$ result in changes to $\mathrm{NAD}(\mathrm{P}) \mathrm{H}$ and FAD fluorescence lifetimes. The strength of the correlations between endogenous fluorescence lifetime variables and extracellular $\mathrm{pH}$ were not conserved across cell lines, with differences being particularly evident in the $\mathrm{NAD}(\mathrm{P}) \mathrm{H}$ lifetime variables and the optical redox ratio. Studies of free FAD, bound FAD, and FMN solutions indicated that changes in cellular FAD lifetimes with $\mathrm{pH}$ are likely due to metabolic and/or enzymatic changes within the cell, rather than microenvironmental changes in $\mathrm{pH}$ around the fluorophore alone. This is consistent with changes in enzyme function that are known to occur with changes in cytosolic and mitochondrial $\mathrm{pH}^{20}$ These results suggest that the relationship between extracellular $\mathrm{pH}$ and endogenous fluorescence lifetimes differ between cell lines, which could provide a method 


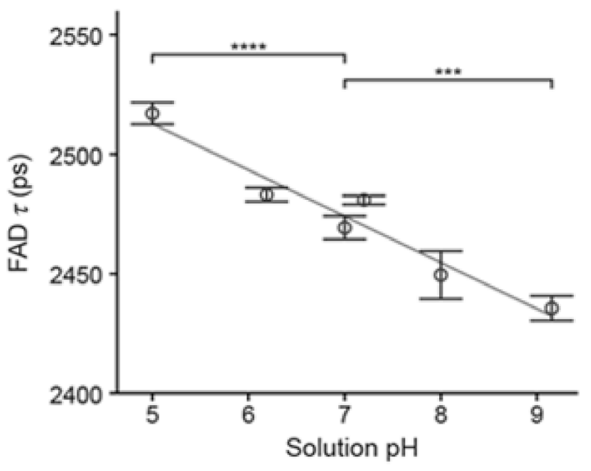

(a)

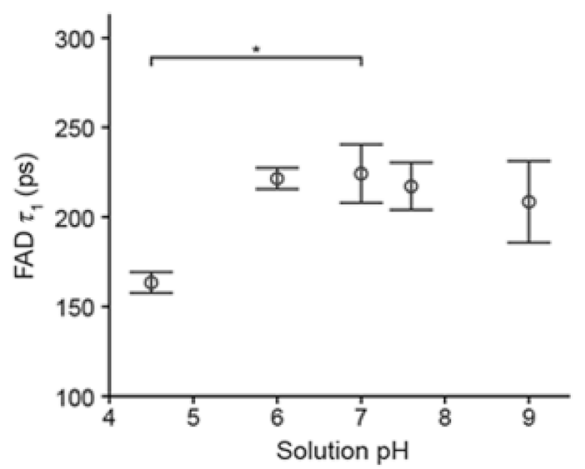

(c)

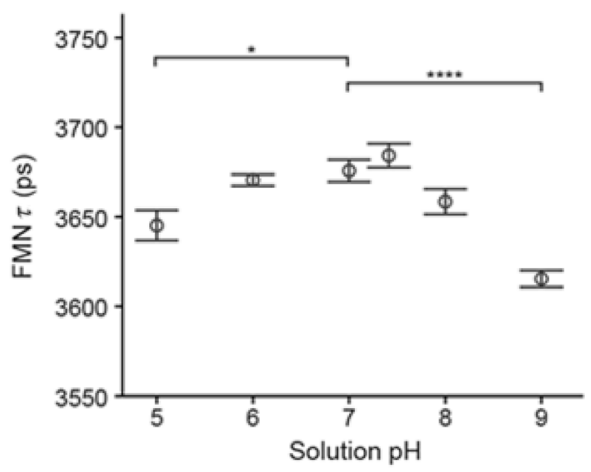

(b)

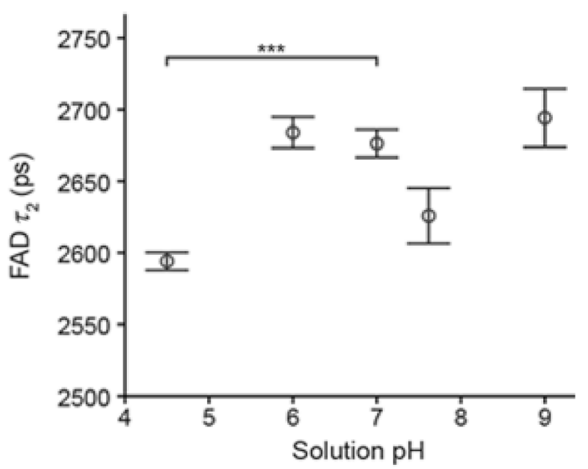

(d)

Fig. 3 Fluorescence lifetimes of FAD and FMN solutions. (a) Fluorescence lifetimes of FAD solutions versus solution $\mathrm{pH}$, mean $\pm 95 \%$ confidence intervals (linear fit is included with $R=-0.8375, n=36$ images). (b) Fluorescence lifetimes of FMN solutions versus solution $\mathrm{pH}$, mean $\pm 95 \%$ confidence intervals ( $n=56$ images). (c) Short fluorescence lifetime of FAD in solution with cholesterol oxidase versus solution $\mathrm{pH}$, mean $\pm 95 \%$ confidence intervals $(n=37$ images). (d) Long fluorescence lifetime of FAD in solution with cholesterol oxidase versus solution $\mathrm{pH}$, mean $\pm 95 \%$ confidence intervals ( $n=37$ images). FAD and FMN solutions in (a) and (b) are fit to one component, FAD-cholesterol oxidase solutions in (c) and (d) are fit to two components. Data presented as mean $\pm 95 \%$ confidence intervals, $p$ values compare group to control at $\mathrm{pH}$ 7.0. ${ }^{* * *} P<0.0001,{ }^{\star * *} P<0.001,{ }^{*} P<0.05$.

of cell phenotyping. This relationship between extracellular $\mathrm{pH}$ and endogenous fluorescence lifetime could also be applicable to quality control of cell conditions during FLIM imaging and to study metabolic changes in cells due to extracellular $\mathrm{pH}$.

\section{Disclosures}

The authors declare no conflicts of interest related to this work.

\section{Acknowledgments}

This work was supported by the National Institutes of Health under Grant Nos. R01 CA185747, R01 CA205101, and R01 CA211082; and the National Science Foundation under Grant No. CBET-1642287. The authors would like to thank R. Datta and J. T. Sharick for their helpful guidance.

\section{References}

1. K. Suhling, P. M. W. French, and D. Phillips, "Time-resolved fluorescence microscopy," Photochem. Photobiol. Sci. 4(1), 13-22 (2005). 
2. J. Hühner et al., "Quantification of riboflavin, flavin mononucleotide, and flavin adenine dinucleotide in mammalian model cells by CE with LED-induced fluorescence detection," Electrophoresis 36(4), 518-525 (2015).

3. C. Kang et al., "Simultaneously quantifying intracellular FAD and FMN using a novel strategy of intrinsic fluorescence four-way calibration," Talanta 197, 105-112 (2019).

4. A. A. Heikal, "Intracellular coenzymes as natural biomarkers for metabolic activities and mitochondrial anomalies," Biomark Med. 4(2), 241-263 (2010).

5. W. D. Lienhart, V. Gudipati, and P. Macheroux, "The human flavoproteome," Arch. Biochem. Biophys. 535(2), 150-162 (2013).

6. J. R. Lakowicz, "Fluorophores," in Principles of Fluorescence Spectroscopy, pp. 63-65, Springer, New York (2006).

7. S. Huang, A. A. Heikal, and W. W. Webb, "Two-photon fluorescence spectroscopy and microscopy of NAD(P)H and flavoprotein," Biophys. J. 82(5), 2811-2825 (2002).

8. J. R. Lakowicz et al., "Fluorescence lifetime imaging of free and protein-bound NADH," Proc. Natl. Acad. Sci. U. S. A. 89, 1271-1275 (1992).

9. N. Nakashima et al., "Picosecond fluorescence lifetime of the coenzyme of D-amino acid oxidase," J. Biol. Chem. 255(11), 5261-5263 (1980).

10. L. Marcu, "Fluorescence lifetime techniques in medical applications," Ann. Biomed. Eng. 40(2), 304-331 (2012).

11. M. A. Yaseen et al., "In vivo imaging of cerebral energy metabolism with two-photon fluorescence lifetime microscopy of NADH," Biomed. Opt. Express 4(2), 307-321 (2013).

12. P. M. Schaefer et al., "NADH autofluorescence: a mark on its way to boost bioenergetic research," Cytometry Part A 95A, 34-46 (2019).

13. K. Awasthi et al., "Sensitive detection of intracellular environment of normal and cancer cells by autofluorescence lifetime imaging," J. Photochem. Photobiol. B: Biol. 165, 256-265 (2016).

14. A. J. Walsh et al., "Quantitative optical imaging of primary tumor organoid metabolism predicts drug response in breast cancer," Cancer Res. 74(18), 5184-5194 (2014).

15. A. J. Walsh et al., "Optical metabolic imaging identifies glycolytic levels, subtypes, and early-treatment response in breast cancer," Cancer Res. 73(20), 6164-6174 (2013).

16. M. C. Skala et al., "In vivo multiphoton microscopy of NADH and FAD redox states, fluorescence lifetimes, and cellular morphology in precancerous epithelia," Proc. Natl. Acad. Sci. U. S. A. 104(49), 19494-19499 (2007).

17. K. Drozdowicz-Tomsia et al., "Multiphoton fluorescence lifetime imaging microscopy reveals free-to-bound NADH ratio changes associated with metabolic inhibition," J. Biomed. Opt. 19(8), 086016 (2014).

18. F. Müller, S. G. Mayhew, and V. Massey, "Effect of temperature on the absorption spectra of free and protein-bound flavines," Biochemistry 12(23), 4654-4662 (1973).

19. J. Chacko and K. Eliceiri, "Autofluorescence lifetime imaging of cellular metabolism: sensitivity toward cell density, $\mathrm{pH}$, intracellular, and intercellular heterogeneity," Cytometry Part A 95A, 56-69 (2019).

20. P. Schaefer et al., "Mitochondrial matrix $\mathrm{pH}$ as a decisive factor in neurometabolic imaging," Neurophotonics 4(4), 045004 (2017).

21. Y. Marunaka, "Roles of interstitial fluid $\mathrm{pH}$ and weak organic acids in development and amelioration of insulin resistance," Biochem. Soc. Trans. 49(2), 715-726 (2021).

22. W. N. Charman et al., "Physicochemical and physiological mechanisms for the effects of food on drug absorption: the role of lipids and pH," J. Pharmaceutical Sci. 86(3), 269-282 (1997).

23. R. Cardone, V. Casavola, and S. Reshkin, "The role of disturbed $\mathrm{pH}$ dynamics and the $\mathrm{Na}+\mathrm{H}+$ exchanger in metastasis," Nat. Rev. Cancer 5(10), 786-795 (2005).

24. R. J. Gillies et al., "pH imaging," IEEE Eng. Med. Biol. Mag. 23(5), 57-64 (2004).

25. M. R. Hight et al., "Multispectral fluorescence imaging to assess $\mathrm{pH}$ in biological specimens," J. Biomed. Opt. 16(1), 016007 (2011).

26. E. K. Rofstad et al., "Acidic extracellular pH promotes experimental metastasis of human melanoma cells in athymic nude mice," Cancer Res. 66(13), 6699-6707 (2006). 
27. M. S. Islam et al., "pH dependence of the fluorescence lifetime of FAD in solution and in cells," Int. J. Mol. Sci. 14, 1952-1963 (2013).

28. S. Ogikubo et al., "Intracellular pH sensing using autofluorescence lifetime microscopy," J. Phys. Chem. 115, 10385-10390 (2011).

29. H. Breitbart, "Effects of ionophores and metabolic inhibitors on protein synthesis in rabbit reticulocytes," Biochim. Biophys. Acta - Nucl. Acids Prot. Synth. 656(2), 160-166 (1981).

30. M. Varnes, K. Glazier, and C. Gray, "PH-dependent effects of the ionophore nigericin on response of mammalian cells to radiation and heat treatment," Radiat. Res. 117(2), 282-292 (1989).

31. M. Erecińska et al., "Relations between intracellular ions and energy metabolism under acidotic conditions: a study with nigericin in synaptosomes, neurons, and C6 glioma cells," J. Neurochem. 61, 1356-1368 (1993).

32. A. Vrielink and S. Ghisla, "Cholesterol oxidase: biochemistry and structural features," FEBS J. 276(23), 6826-6843 (2009).

33. A. J. W. G. Visser et al., "Time-resolved fluorescence studies of flavodoxin: demonstration of picosecond fluorescence lifetimes of FMN in Desulfovibrio flavodoxins," FEBS Lett. 224(2), 406-410 (1987).

34. M. W. Conklin et al., "Fluorescence lifetime imaging of endogenous fluorophores in histopathology sections reveals differences between normal and tumor epithelium in carcinoma in situ of the breast," Cell Biochem. Biophys. 53(3), 145-157 (2009).

35. A. V. Meleshina et al., "Two-photon FLIM of NAD(P)H and FAD in mesenchymal stem cells undergoing either osteogenic or chondrogenic differentiation," Stem Cell Res. Ther. 8(1) (2017).

36. R. Penjweini et al., "Single cell-based fluorescence lifetime imaging of intracellular oxygenation and metabolism," Redox Biol. 34, 101549 (2020).

37. A. J. Walsh and M. C. Skala, "An automated image processing routine for segmentation of cell cytoplasms in high-resolution autofluorescence images," Proc. SPIE 8948, 89481M (2014).

38. G. A. Baker et al., "Assessment of one- and two-photon excited luminescence for directly measuring $\mathrm{O}_{2}, \mathrm{pH}, \mathrm{Na}+, \mathrm{Mg}^{2+}$, or $\mathrm{Ca}^{2+}$ in optically dense and biologically relevant samples," Appl. Spectrosc. 56(4), 455-463 (2002).

39. M. Fellenz and L. Gerweck, "Influence of extracellular $\mathrm{pH}$ on intracellular $\mathrm{pH}$ and cell energy status: relationship to hyperthermic sensitivity," Radiat. Res. 116(2), 305-312 (1988).

40. G. Bischof et al., "Effects of extracellular pH on intracellular pH-regulation and growth in a human colon carcinoma cell-line," Biochim. Biophys Acta 1282(1), 131-139 (1996).

41. N. E. El-Naggar et al., "Purification, characterization and amino acid content of cholesterol oxidase produced by Streptomyces aegyptia NEAE 102,” BMC Microbiol. 17(1), 76 (2017).

Biographies of the authors are not available. 